\title{
HUBUNGAN FAKTOR LINGKUNGAN FISIK RUMAH DAN PERILAKU HIDUP BERSIH DAN SEHAT DENGAN KEJADIAN INFEKSI SALURAN PERNAPASAN AKUT PADA BALITA DI WILAYAH KERJA PUSKESMAS 1 PURWOKERTO TIMUR TAHUN 2018
}

\author{
Rodina Asmar Raenti ${ }^{1)}$, Asep Tata Gunawan ${ }^{2)}$, Agus Subagiyo ${ }^{3)}$ \\ Jurusan Kesehatan Lingkungan, Politeknik Kesehatan Kemenkes Semarang, \\ Jl. Raya Baturaden KM 12 Purwokerto, Indosensia
}

\begin{abstract}
Abstrak
Latar Belakang Infeksi Saluran Pernapasan Akut (ISPA) erat kaitannya dengan kondisi fisik rumah dan Perilaku Hidup Bersih dan Sehat (PHBS) yang kurang baik dapat menyebabkan balita terinfeksi karena balita sangat rentan terhadap berbagai macam penyakit. Jenis Penelitain observasi analitik dengan pendekatan case control jumlah responden sebanyak 70 orang, 35 sebagai kasus dan 35 sebagai kontrol. Variabel yang diteliti adalah ventilasi, pencahayaan, jenis lantai, jenis dinding, kepadatan penghuni, kelembaban, suhu, kebiasaan merokok, penggunaan bahan bakar memasak dan penggunaan obat nyamuk. Hasil analisis menunjukan faktor lingkungan fisik rumah yang memiliki hubungan adalah ventilasi $(p=0,000$, OR=14,222), kepadatan penghuni $(p=0,000$, OR=15,000), kelembaban $(p=0,026, O R=5,053)$, suhu $(p=0,026, O R=3,574)$. Untuk analisis multivariate yang paling signifikan adalah kepadatan penghuni $(p=0,000, O R=17,297)$ dan ventilasi $(p=0,000$, $O R=9,611)$. Pada variabel pencahayaan, jenis lantai, jenis dinding, kebiasaan merokok, bahan bakar memasak dan penggunaan obat nyamuk tidak memiliki hubungan yang signifikan akan tetapi beresiko. Kesimpulan dari penelitian ini adalah faktor lingkungan fisik rumah dan PHBS dapat menjadi faktor resiko terjadinya penyakit ISPA. Faktor yang memiliki hubungan signifikan yaitu ventilasi, kepadatan penghuni, kelembaban, suhu. Disarankan agar meningkatkan perilaku hidup bersih dan sehat agar terhindar dari penyakit.
\end{abstract}

Kata Kunci : Perilaku hidup bersih dan sehat; ISPA; Balita

\begin{abstract}
Abstrack
Acute Respiratory Infection (ARI) closely related with the physical condition of house and a bad Healthy and Clean Living Behavior (CHB) can cause the children are infected because the children are very susceptible to the various of diseases. The method that is used in this research is analytic observation with case control approach. The number of respondents are 70 people, 35 people as the case and 35 as the control. Variable that are inspected are ventilation, lighting, kind of the floor, kind of the wall, occupants density, humidity, temperature, smooking habit, the use of fuel for cooking, and the use of insect repellent.The result of research is show that the physical environment factor of the house which is has the corelation are ventilation $(p=0,000, O R=14,222)$, occupant density $(p=0,000, O R=15,000)$, humidity $(p=$ $0,026, O R=5,053)$, temperature $(p=0,026, O R=3,574)$. The most significant in the multivariate analysis are occupant density $(p=0,000, O R=17,297)$ and ventilation $(p=0,000, O R=9,611)$. In the lighting variable, kind of the floor, kind of the wall, smooking habit, the cooking fuel and the use of insect repellent haven't significant corellation but is still risky. The conclusion of this research is the physical house environment factor of the house and CHB can be risk factor of ARI disease. Factors that have a significant corelation are ventilation, occupant density, humidity, temperature. Researcher is advice to increase the healthy living and clean to avoid the illness.
\end{abstract}

Keywords : Healthy and Clean Living Behavior; ARI; Toddler

\footnotetext{
$\left.{ }^{1}\right)$ Email: asmarraenti17@gmail.com

$\left.{ }^{2}\right)$ Email: aseptatagunawan@yahoo.co.id

${ }^{3}$ )Email: agusgiyo@yahoo.co.id
} 


\section{PENDAHULUAN}

Banyak faktor yang mempengaruhi kesehatan baik kesehatan individu maupun kesehatan masyarakat. Menurut Hendrick L.Blum faktor-faktor yang mempengaruhi derajat kesehatan ada 4 yaitu : lingkungan, perilaku , pelayanan kesehatan , dan keturunan. Pembangunan kesehatan bertujuan untuk meningkatkan kesadaran, kemauan, dan kemampuan hidup sehat bagi setiap orang agar terwujud derajat kesehatan masyarakat yang setinggi-tingginya, sebagai investasi bagi pembangunan sumber daya manusia yang produktif secara social dan ekonomis (UndangUndang Kesehatan Republik Indonesia Nomor 36 Tahun 2009). Hal ini dapat dilihat dari tingginya angka kesakitan dan kematian akibat ISPA (Kemenkes RI, 2010). ISPA (Infeksi Saluran Pernapasan Atas) masih merupakan masalah kesehatan yang penting, karena ISPA (seperti; sinusitis, common cold, influenza, pneumonia) penyebab kematian bayi dan balita yang cukup tinggi yaitu kira-kira 1 dari 4 kematian yang terjadi. Setiap anak diperkirakan mengalami 3-6 episode ISPA setiap tahunnya. 40\% - 60\% dari kunjungan di Puskesmas adalah oleh penyakit ISPA. Dari seluruh kematian yang disebabkan oleh ISPA mencakup 20\%-30\%.

ISPA selalu menduduki peringkat pertama dari 10 penyakit terbanyak di Indonesia. Berdasarkan hasil Riskesdas tahun 2013, prevalensi ISPA ditemukan sebesar 25,0\%. Karakteristik penduduk dengan ISPA yang tertinggi terjadi pada kelompok umur 1-4 tahun yaitu sebesar 25,8\%. Menurut jenis kelamin, tidak berbeda antara laki-laki dan perempuan yaitu sebesar $13,7 \%$ untuk laki-laki dan $13,8 \%$ untuk perempuan. Menurut data Provinsi Jawa Tengah tahun 2013 salah satu penyebab angka kematian balita adalah penyakit ISPA, di Jawa Tengah presentasi penemuan dan penanganan penderita ISPA pada balita tahun 2013 sebesar 73,165 kasus $(25,85 \%)$ meningkat dibandingkan tahun 2012 sebesar 24,74\%. (Profil Kesehatan Provinsi Jawa Tengah, 2013).

Menurut Profil Dinas Kesehatan Kabupaten Banyumas menyebutkan bahwa jumlah kasus penyakit ISPA di Kabupaten Banyumas pada tahun 2016 Penyakit ISPA di wilayah kerja Puskemas 1 Purwokerto Timur menempati posisi tertinggi se wilayah Kabupaten Banyumas, yaitu 274 kasus dengan jumlah balita laki-laki 932 dan balita perempuan 910 . Tingginya angka kejadian ISPA di wilayah kerja Puskesmas 1 Purwokerto Timur bisa disebabkan oleh faktor lingkungan fisik rumah dan faktor Perilaku Hidup Bersih dan Sehat (PHBS) dimana dalam pelaksanaannya masih sulit dilaksanakan secara maksimal oleh sebagian besar masyarakat. Penerapan perilaku hidup bersih dan sehat (PHBS) merupakan langkah ampuh untuk menangkal penyakit. Pengetahuan tentang PHBS diperlukan bagi keluarga dalam upaya untuk mengajak dan mendorong kemandirian keluarga untuk berperilaku hidup bersih sehat (Nadesul, 2008). Melihat tingginya kasus Infeksi Saluran Pernapasan Akut (ISPA) di wilayah kerja Puskesman 1 Purwokerto Timur, maka penulis tertarik untuk melakukan penelitian dengan mengambil berjudul "Hubungan Faktor Lingkungan Fisik Rumah dan Perilaku Hidup Bersih dan Sehat (PHBS) dengan Kejadian Infeksi Saluran Pernapasan Akut (ISPA) pada Balita di Wilayah Puskesmas 1 Purwokerto Timur Tahun 2018".

Berdasarkan uraian latar belakang masalah, maka penulis membuat rumusan masalah dalam penelitian ini adalah "Apakah ada Hubungan antara Faktor Lingkungan Fisik Rumah dan Perilaku Hidup Bersih dan Sehat (PHBS) dengan Kejadian Infeksi Saluran Pernapasan Akut (ISPA) pada Balita di Wilayah Puskesmas 1 Purwokerto Timur Tahun 2018”.

Tujuan penelitian ini adalah mengetahui hubungan lingkungan fisik rumah dan perillaku hidup bersih dan sehat terhadap kejadian ISPA pada balita di wilayah kerja Puskesmas 1 Purwokerto Timur.

\section{BAHAN DAN METODE}

Jenis penelitian ini merupakan suatu penelitian atau observasi analitik yang mengungkapkan bagaimana sebuah faktor resiko dipelajari dengan melihat ke belakang (pengalaman atau kejadian yang telah berlalu) dengan pendekatan case control. Jumlah sampel sebanyak 70 sampel, 35 sampel sebagai kasus dan 35 sampel sebagai control. Populasi penelitian ini adalah semua balita yang berobat ke Puskesmas yang menderita ISPA pada bulan November tahun 2017.

Variabel bebas yaitu variabel yang berpengaruh atau yang menyebabkan berubahnya variabel terikat dan merupakan variabel pengaruh yang paling utama. Variabel bebas dalam penelitian ini adalah persyaratan rumah sehat yang terdiri dari ventilasi, pencahayaan, jenis lantai, jenis dinding, kepadatan penghuni, kelembaban, suhu, kebiasaan merokok, penggunaan bahan bakar memasak dan penggunaan obat nyamuk. Variabel terikat, yaitu variabel yang diduga nilainya akan berubah karena adanya pengaruh dari variabel 
bebas.Variabel terikat dalam penelitian ini adalah Kejadian ISPA pada Balita.

Instrumen penelitian ini merupakan alat untuk mengumpulkan data dari suatu penelitian. Instrumen penelitian adalah alat atau fasilitas yang digunakan oleh peneliti dalam meneliti dan mengumpulkan data agar penelitiannya lebih mudah dan hasilnya akan lebih baik dalam arti tepat, lengkap, sistematis sehingga lebih mudah untuk diolah. Instrumen yang digunakan dalam penelitian ini adalah checklist, rollmeter, hygrometer, lux meter. Hasil dianalisis dengan menggunakan soft ware analisis data yang terdiri dari analisis univariate, analisis bivariate menggunakan uji chi square dan analisis multivariate menggunakan uji regresi logistic.

\section{HASIL DAN PEMBAHASAN}

1. Hubungan ventilasi dengan kejadian ISPA pada balita

\begin{tabular}{|c|c|c|c|}
\hline Ventilasi & Kasus & Kontrol & Jumlah \\
\hline $\begin{array}{l}\text { Tidak } \\
\text { memenuhi } \\
\text { syarat }\end{array}$ & $\begin{array}{l}32 \\
(91,4 \%)\end{array}$ & $\begin{array}{l}15 \\
(42,9 \%)\end{array}$ & $\begin{array}{l}47 \\
(67,1 \%)\end{array}$ \\
\hline $\begin{array}{l}\text { Memenuhi } \\
\text { syarat }\end{array}$ & $\begin{array}{l}3 \\
(8,6 \%)\end{array}$ & $\begin{array}{l}20 \\
(57,1 \%)\end{array}$ & $\begin{array}{l}23 \\
(32,9 \%)\end{array}$ \\
\hline Total & $\begin{array}{l}35 \\
(100 \%)\end{array}$ & $\begin{array}{l}35 \\
(100 \%)\end{array}$ & $\begin{array}{l}70 \\
(100 \%)\end{array}$ \\
\hline \multicolumn{4}{|c|}{$\begin{array}{c}\text { P-value }: 0,000, \text { OR : } 14,222, \mathrm{CI}=3,651- \\
55,394\end{array}$} \\
\hline
\end{tabular}

Berdasarkan hasil penelitian menunjukkan bahwa ventilasi yang tidak memenuhi syarat pada kelompok kasus proporsi lebih besar yaitu $(91,4 \%)$ dibandingkan dengan kelompok control $(42,9 \%)$, sedangkan untuk ventilasi yang memenuhi syarat pada kelompok kontrol proporsi lebih besar $(57,1 \%)$ dibandingkan dengan kelompok kasus yaitu $(8,6 \%)$.

Berdasarkan hasil uji statistik Chi Square menunjukkan nilai P-value 0,000 dengan demikian nilai P-value lebih kecil dari $\alpha: 0,05$ maka dinyatakan terdapat hubungan yang signifikan antara ventilasi dengan kejadian ISPA pada balita, pengujian Odds ratio menunjukkan nilai OR : 14,222 (95\% Confidence Interval (CI) $=3,651-55,394)$. Responden yang ventilasinya tidak memenuhi syarat memiliki risiko dapat terkena ISPA 14,222 kali lebih besar dibandingkan dengan responden yang ventilasi memenuhi syarat.
2. Hubungan pencahayaan dengan kejadian ISPA pada balita

\begin{tabular}{|c|c|c|c|}
\hline Pencahayaan & Kasus & $\begin{array}{c}\text { Kontr } \\
\text { ol }\end{array}$ & Jumlah \\
\hline $\begin{array}{l}\text { Tidak } \\
\text { memenuhi } \\
\text { syarat }\end{array}$ & $\begin{array}{l}33 \\
(94,3 \%)\end{array}$ & $\begin{array}{l}28 \\
(80,0 \%)\end{array}$ & $\begin{array}{l}61 \\
(87,1 \%)\end{array}$ \\
\hline $\begin{array}{l}\text { Memenuhi } \\
\text { syarat }\end{array}$ & $\begin{array}{l}2 \\
(5,7 \%)\end{array}$ & $\begin{array}{l}7 \\
(20,0 \%)\end{array}$ & $9(12,9 \%)$ \\
\hline Total & $\begin{array}{l}35 \\
(100 \%) \\
\end{array}$ & $\begin{array}{l}35 \\
(100 \%) \\
\end{array}$ & $\begin{array}{l}70 \\
(100 \%) \\
\end{array}$ \\
\hline \multicolumn{4}{|c|}{$\begin{array}{c}\text { P-value }: 0,153, \mathrm{OR}: 4,125, \mathrm{CI}=0,792- \\
21,483\end{array}$} \\
\hline
\end{tabular}

Berdasarkan hasil penelitian menunjukkan bahwa pencahayaan yang tidak memenuhi syarat pada kelompok kasus proporsi lebih besar yaitu (94,3\%) dibandingkan dengan kelompok kontrol $(80,0 \%)$, sedangkan untuk pencahayaan yang memenuhi syarat pada kelompok kontrol proporisnya lebih besar $(20,0 \%)$ dibandingkan dengan kelompok kasus yaitu $(5,7 \%)$.

Berdasarkan hasil uji statistik Chi Square menunjukkan nilai P-value 0,153 dengan demikian nilai $P$-value lebih besar dari $\alpha$ : 0,05 maka dinyatakan tidak terdapat hubungan yang signifikan antara pencahayaan dengan kejadian ISPA pada balita, pengujian Odds ratio menunjukkan nilai OR : 4,125 (95\% Confidence Interval $(\mathrm{CI})=0,792-21,483)$. Responden yang pencahayaan tidak memenuhi syarat memiliki risiko dapat terkena ISPA 4,125 kali lebih besar dibandingkan dengan responden yang pencahayaannya memenuhi syarat.

3. Hubungan jenis lantai dengan kejadian ISPA pada balita

\begin{tabular}{clll}
\hline $\begin{array}{c}\text { Jenis } \\
\text { Lantai }\end{array}$ & Kasus & Kontrol & Jumlah \\
\hline Tidak & 11 & 7 & 18 \\
memenu & $(31,4 \%$ & $(20,0 \%)$ & $(25,7 \%)$ \\
hi syarat & ) & & 52 \\
Memenu & 24 & 28 & $(74,3 \%)$ \\
hi syarat & $(68,6 \%$ & $(80,0 \%)$ & 70 \\
& ) & 35 & $(100 \%)$ \\
Total & 35 & $(100 \%)$ & $(100 \%)$ \\
\hline P-value : 0,412, OR : $1,833, \mathrm{CI}=0,641-$ \\
\multicolumn{4}{c}{5,471} \\
\hline
\end{tabular}

Berdasarkan hasil penelitian menunjukkan bahwa jenis lantai yang tidak memenuhi syarat pada kelompok kasus proporsi lebih besar yaitu $(31,4 \%)$ dibandingkan dengan kelompok kontrol 
(20,0\%), sedangkan untuk jenis lantai yang memenuhi syarat pada kelompok kontrol proporisnya lebih besar $(80,0 \%)$ dibandingkan dengan kelompok kasus yaitu $(68,6 \%)$.

Berdasarkan hasil uji statistik Chi Square menunjukkan nilai P-value 0,412 dengan demikian nilai P-value lebih besar dari $\alpha: 0,05$ maka dinyatakan tidak terdapat hubungan yang signifikan antara jenis lantai dengan kejadian ISPA pada balita, pengujian Odds ratio menunjukkan nilai OR : 1,833 (95\% Confidence Interval $(\mathrm{CI})=0,614-5,471)$. Responden yang jenis lantainya tidak memenuhi syarat memiliki risiko dapat terkena ISPA 1,833 kali lebih besar dibandingkan dengan responden yang jenis lantainya memenuhi syarat.

4. Hubungan jenis dinding dengan kejadian ISPA pada balita

\begin{tabular}{llll}
\hline \multicolumn{1}{c}{$\begin{array}{c}\text { Jenis } \\
\text { Dinding }\end{array}$} & Kasus & Kontrol & Jumlah \\
\hline $\begin{array}{l}\text { Tidak } \\
\text { memenuhi } \\
\text { syarat }\end{array}$ & 3 & 2 & $5(7,1 \%)$ \\
Memenuhi & 32 & 33 & 65 \\
syarat & $(91,4 \%$ & $(9,7 \%)$ & \\
& ) & & $(92,9 \%)$ \\
\multicolumn{1}{c}{ Total } & 35 & 35 & 70 \\
& $(100 \%)$ & $(100 \%)$ & $(100 \%)$ \\
\hline \multicolumn{4}{c}{ P-value : 1,000, OR : $1,547, \mathrm{CI}=0,242-$} \\
\hline
\end{tabular}

Berdasarkan hasil penelitian menunjukkan bahwa jenis dinding yang tidak memenuhi syarat pada kelompok kasus proporsi lebih besar yaitu $(8,6 \%)$ dibandingkan dengan kelompok kontrol $(5,7 \%)$, sedangkan untuk jenis dinding yang memenuhi syarat pada kelompok kontrol proporisnya lebih besar $(94,3 \%)$ dibandingkan dengan kelompok kasus yaitu $(91,4 \%)$.

Berdasarkan hasil uji statistik Chi Square menunjukkan nilai P-value 1,000 dengan demikian nilai $\mathrm{P}$-value lebih besar dari $\alpha: 0,05$ maka dinyatakan tidak terdapat hubungan yang signifikan antara jenis dinding dengan kejadian ISPA pada balita, pengujian Odds ratio menunjukkan nilai OR : 1,547 (95\% Confidence Interval $(\mathrm{CI})=0,242-9,878)$. Responden yang jenis dindingnya tidak memenuhi syarat memiliki risiko dapat terkena ISPA 1,547 kali lebih besar dibandingkan dengan responden yang jenis dindingnya memenuhi syarat.

5. Hubungan kepadatan penghuni dengan kejadian ISPA pada balita

\begin{tabular}{|c|c|c|c|}
\hline $\begin{array}{l}\text { Kepadatan } \\
\text { Penghuni }\end{array}$ & Kasus & Kontrol & Jumlah \\
\hline $\begin{array}{l}\text { Tidak } \\
\text { memenuhi } \\
\text { syarat }\end{array}$ & $\begin{array}{l}25 \\
(71,4 \%)\end{array}$ & $\begin{array}{l}5 \\
(14,3 \%)\end{array}$ & $\begin{array}{l}30 \\
(42,9 \%)\end{array}$ \\
\hline $\begin{array}{l}\text { Memenuhi } \\
\text { syarat }\end{array}$ & $\begin{array}{l}10 \\
(28,6 \%)\end{array}$ & $\begin{array}{l}30 \\
(85,7 \%)\end{array}$ & $\begin{array}{l}40 \\
(57,1 \%)\end{array}$ \\
\hline Total & $\begin{array}{l}35 \\
(100 \%)\end{array}$ & $\begin{array}{l}35 \\
(100 \%)\end{array}$ & $\begin{array}{l}70 \\
(100 \%)\end{array}$ \\
\hline \multicolumn{4}{|c|}{$\begin{array}{c}\text { P-value : } 0,000, \mathrm{OR}: 15,000, \mathrm{CI}=4,529- \\
49,680)\end{array}$} \\
\hline
\end{tabular}

Berdasarkan hasil penelitian menunjukkan bahwa kepadatan penghuni yang tidak memenuhi syarat pada kelompok kasus proporsi lebih besar yaitu $(71,4 \%)$ dibandingkan dengan kelompok kontrol $(14,3 \%)$, sedangkan untuk kepadatan penghuni yang memenuhi syarat pada kelompok kontrol proporsi lebih besar $(85,7 \%)$ dibandingkan dengan kelompok kasus yaitu $(28,6 \%)$.

Berdasarkan hasil uji statistik Chi Square menunjukkan nilai P-value 0,000 dengan demikian nilai P-value lebih kecil dari $\alpha$ : 0,05 maka dinyatakan terdapat hubungan yang signifikan antara kepadatan penghuni dengan kejadian ISPA pada balita, pengujian Odds ratio menunjukkan nilai OR : 15,000 (95\% Confidence Interval $(\mathrm{CI})=4,529-49,680)$. Responden yang memiliki kepadatan penghuni yang tidak memenuhi syarat memiliki risiko dapat terkena ISPA 15,000 kali lebih besar dibandingkan dengan responden yang kepadatan penghuninya memenuhi syarat.

6. Hubungan Kelembaban dengan kejadian ISPA pada balita

\begin{tabular}{|c|c|c|c|}
\hline Kelembaban & Kasus & Kontrol & Jumlah \\
\hline $\begin{array}{l}\text { Tidak } \\
\text { memenuhi } \\
\text { syarat }\end{array}$ & $\begin{array}{l}30 \\
(85,7 \%)\end{array}$ & $\begin{array}{l}19 \\
(54,3 \%)\end{array}$ & $\begin{array}{l}49 \\
(70,0 \% \\
)\end{array}$ \\
\hline $\begin{array}{l}\text { Memenuhi } \\
\text { syarat }\end{array}$ & $\begin{array}{l}5 \\
(14,3 \%)\end{array}$ & $\begin{array}{l}16 \\
(45,7 \%)\end{array}$ & $\begin{array}{l}21 \\
(30,0 \%\end{array}$ \\
\hline Total & $\begin{array}{l}35 \\
(100 \%) \\
\end{array}$ & $\begin{array}{l}35 \\
(100 \%) \\
\end{array}$ & $\begin{array}{l}70 \\
(100 \%)\end{array}$ \\
\hline $\mathrm{P}$-value : & $\begin{array}{r}, 009, \text { OR } \\
16,0\end{array}$ & $53, \mathrm{CI}=$ & $589-$ \\
\hline
\end{tabular}

Berdasarkan hasil penelitian menunjukkan bahwa kelembaban yang tidak memenuhi syarat pada kelompok kasus proporsi lebih besar yaitu $(85,7 \%)$ dibandingkan dengan kelompok kontrol 
$(54,3 \%)$, sedangkan untuk kelembaban yang memenuhi syarat pada kelompok kontrol proporisnya lebih besar $(45,7 \%)$ dibandingkan dengan kelompok kasus yaitu (14,3\%).

Berdasarkan hasil uji statistik Chi Square menunjukkan nilai P-value 0,009 dengan demikian nilai P-value lebih kecil dari $\alpha: 0,05$ maka dinyatakan terdapat hubungan yang signifikan antara kelembaban dengan kejadian ISPA pada balita, pengujian Odds ratio menunjukkan nilai OR : 5,053 (95\% Confidence Interval $(\mathrm{CI})=1,589-16,069)$. Responden yang memiliki kelembaban yang tidak memenuhi syarat memiliki risiko dapat terkena ISPA 5,053 kali lebih besar dibandingkan dengan responden yang kelembabannya memenuhi syarat

7. Hubungan suhu dengan kejadian ISPA pada balita

\begin{tabular}{|c|c|c|c|}
\hline Suhu & Kasus & Kontrol & Jumlah \\
\hline $\begin{array}{l}\text { Tidak } \\
\text { memenuh } \\
\text { i syarat }\end{array}$ & $\begin{array}{l}27 \\
(77,1 \%)\end{array}$ & $\begin{array}{l}17 \\
(48,6 \%)\end{array}$ & $\begin{array}{l}44 \\
(62,9 \%)\end{array}$ \\
\hline $\begin{array}{l}\text { Memenuh } \\
\text { i syarat }\end{array}$ & $\begin{array}{l}8 \\
(22.9 \%)\end{array}$ & $\begin{array}{l}18 \\
(51,4 \%)\end{array}$ & $\begin{array}{l}26 \\
(37.1 \%)\end{array}$ \\
\hline Total & $\begin{array}{l}35 \\
(100 \%)\end{array}$ & $\begin{array}{l}35 \\
(100 \%)\end{array}$ & $\begin{array}{l}70 \\
(100 \%)\end{array}$ \\
\hline \multicolumn{4}{|c|}{$\begin{array}{c}\text { P-value }: 0,026, \mathrm{OR}: 3,574, \mathrm{CI}=1,275- \\
10,014)\end{array}$} \\
\hline
\end{tabular}

Berdasarkan hasil penelitian menunjukkan bahwa suhu yang tidak memenuhi syarat pada kelompok kasus proporsi lebih besar yaitu $(77,1 \%)$ dibandingkan dengan kelompok kontrol $(48,6 \%)$, sedangkan untuk suhu yang memenuhi syarat pada kelompok kontrol proporisnya lebih besar yaitu $(51,4 \%)$ dibandingkan dengan kelompok kasus yaitu $(22,9 \%)$.

Berdasarkan hasil uji statistik Chi Square menunjukkan nilai P-value 0,026 dengan demikian nilai $\mathrm{P}$-value lebih kecil dari $\alpha: 0,05$ maka dinyatakan terdapat hubungan yang signifikan antara suhu dengan kejadian ISPA pada balita, pengujian Odds ratio menunjukkan nilai OR : 3,574 $(95 \%$ Confidence Interval $(\mathrm{CI})=$ 1,275 - 10,014). Responden yang memiliki suhu yang tidak memenuhi syarat memiliki risiko dapat terkena ISPA 3,574 kali lebih besar dibandingkan dengan responden yang suhunya memenuhi syarat.

8. Hubungan kebiasaan merokok dengan kejadian ISPA pada balita

\begin{tabular}{|c|c|c|c|}
\hline $\begin{array}{l}\text { Anggota } \\
\text { Kebiasaan } \\
\text { Merokok }\end{array}$ & Kasus & Kontrol & Jumlah \\
\hline $\begin{array}{l}\text { Tidak } \\
\text { memenuhi } \\
\text { syarat }\end{array}$ & $\begin{array}{l}28 \\
(80,0 \%)\end{array}$ & $\begin{array}{l}30 \\
(85,7 \%)\end{array}$ & $\begin{array}{l}58 \\
(82,9 \%)\end{array}$ \\
\hline $\begin{array}{l}\text { Memenuhi } \\
\text { syarat }\end{array}$ & $\begin{array}{l}7 \\
(20,0 \%)\end{array}$ & $\begin{array}{l}5 \\
(14,3 \%)\end{array}$ & $\begin{array}{l}12 \\
(17,1 \%)\end{array}$ \\
\hline Total & $\begin{array}{l}35 \\
(100 \%)\end{array}$ & $\begin{array}{l}35 \\
(100 \%)\end{array}$ & $\begin{array}{l}70 \\
(100 \%)\end{array}$ \\
\hline \multicolumn{4}{|c|}{$\mathrm{P}$-value : $0,751, \mathrm{OR}: 0,667, \mathrm{CI}=0,190-2,345)$} \\
\hline
\end{tabular}

Berdasarkan hasil penelitian menunjukkan bahwa kebiasaan merokok yang tidak memenuhi syarat pada kelompok kasus proporsi lebih kecil yaitu $(80,0 \%)$ dibandingkan dengan kelompok kontrol $(85,7 \%)$, sedangkan untuk kebiasaan merokok yang memenuhi syarat pada kelompok kontrol proporisnya lebih kecil yaitu (14,3\%) dibandingkan dengan kelompok kasus yaitu $(20,0 \%)$

Berdasarkan hasil uji statistik Chi Square menunjukkan nilai P-value 0,751 dengan demikian nilai P-value lebih besar dari $\alpha: 0,05$ maka dinyatakan tidak terdapat hubungan yang signifikan antara kebiasaan merokok dengan kejadian ISPA pada balita, pengujian Odds ratio menunjukkan nilai OR : 0,677 (95\% Confidence Interval $(\mathrm{CI})=0,190-2,345)$. Responden yang tidak memenuhi syarat memiliki risiko dapat terkena ISPA 0,677 kali lebih besar dibandingkan responden dengan yang memenuhi syarat.

9. Hubungan kebiasaan merokok dengan kejadian ISPA pada balita

\begin{tabular}{|c|c|c|c|}
\hline $\begin{array}{l}\text { Anggota } \\
\text { Kebiasaan } \\
\text { Merokok }\end{array}$ & Kasus & Kontrol & Jumlah \\
\hline $\begin{array}{l}\text { Tidak } \\
\text { memenuhi } \\
\text { syarat }\end{array}$ & $\begin{array}{l}28 \\
(80,0 \%)\end{array}$ & $\begin{array}{l}30 \\
(85,7 \%)\end{array}$ & $\begin{array}{l}58 \\
(82,9 \%)\end{array}$ \\
\hline $\begin{array}{l}\text { Memenuhi } \\
\text { syarat }\end{array}$ & $\begin{array}{l}7 \\
(20,0 \%)\end{array}$ & $\begin{array}{l}5 \\
(14,3 \%)\end{array}$ & $\begin{array}{l}12 \\
(17,1 \%)\end{array}$ \\
\hline Total & $\begin{array}{l}35 \\
(100 \%)\end{array}$ & $\begin{array}{l}35 \\
(100 \%)\end{array}$ & $\begin{array}{l}70 \\
(100 \%)\end{array}$ \\
\hline \multicolumn{4}{|c|}{$\begin{array}{c}\text { P-value }: 0,751, \mathrm{OR}: 0,667, \mathrm{CI}=0,190- \\
2,345)\end{array}$} \\
\hline
\end{tabular}

Berdasarkan hasil penelitian menunjukkan bahwa kebiasaan merokok yang tidak memenuhi syarat pada kelompok kasus proporsi lebih kecil yaitu $(80,0 \%)$ dibandingkan dengan kelompok kontrol $(85,7 \%)$, sedangkan untuk kebiasaan merokok yang memenuhi syarat pada kelompok kontrol proporisnya lebih kecil yaitu (14,3\%) 
dibandingkan dengan kelompok kasus yaitu $(20,0 \%)$.

Berdasarkan hasil uji statistik Chi Square menunjukkan nilai P-value 0,751 dengan demikian nilai P-value lebih besar dari $\alpha: 0,05$ maka dinyatakan tidak terdapat hubungan yang signifikan antara kebiasaan merokok dengan kejadian ISPA pada balita, pengujian Odds ratio menunjukkan nilai OR : 0,677 (95\% Confidence Interval $(\mathrm{CI})=0,190-2,345)$. Responden yang tidak memenuhi syarat memiliki risiko dapat terkena ISPA 0,677 kali lebih besar dibandingkan responden dengan yang memenuhi syarat.

\section{Multivariat}

Multivariate dilakukan untuk mengetahui kondisi fisik rumah yang paling berpengaruh secara bersama-sama terhadap kejadian ISPA pada balita.

Variabel kandidat

\begin{tabular}{llccc}
\hline $\begin{array}{l}\mathrm{N} \\
\mathrm{o}\end{array}$ & Variabel & $\begin{array}{c}\mathrm{P}- \\
\text { Value }\end{array}$ & OR & $\mathrm{CI}$ \\
\hline 1 & Ventilasi & 0,000 & 14,222 & $\begin{array}{l}3,651- \\
55,394\end{array}$ \\
& & & & $0,792-$ \\
\hline 2 & $\begin{array}{l}\text { Pencahay } \\
\text { aan }\end{array}$ & 0,153 & 4,125 & 21,483 \\
& & & $4,529-$ \\
3 & Kepadaat & & & 49,680 \\
& an & 0,000 & 15,000 & \\
& Penghuni & & & $\begin{array}{l}1,589- \\
16,069\end{array}$ \\
\hline 4 & Kelemba & 0,009 & 5,053 & $1,275-$ \\
& ban & & & 10,014 \\
\hline 5 & Suhu & 0,026 & 3,574 & \\
& & & & \\
& & &
\end{tabular}

\section{Hasil uji statistic multivariate}

\begin{tabular}{lccccc}
\hline $\mathrm{N}$ & Komp & $\mathrm{B}$ & Nilai & & \\
$\mathrm{O}$ & onen & $\mathrm{P}-$ & $\mathrm{OR}$ & & \\
& & value & & IV. & SIMPULAN DAN SARAN
\end{tabular}

\begin{tabular}{llllr}
\hline 1 & Ventilasi & 2,263 & 0,003 & 9,611 \\
& $\begin{array}{l}\text { Kepa } \\
\text { datan }\end{array}$ & 2,708 & 0,000 & 17,297 \\
& $\begin{array}{l}\text { Pengh } \\
\text { uni }\end{array}$ & & & \\
& & & \\
\hline & Constant & $-2,663$ & 0,000 & 0,070 \\
\hline
\end{tabular}

Hasil uji multivariate menggunakan regresi logistic metode backward-LR. Menurut R. Topan
Aditya Rahman (2015) adapun syarat variabel kandidat multivariat yang dimana akan masuk dalam analisis multivariat yaitu variabel yang mempunyai nilai $\mathrm{p}<0,25$. Dari ke 5 (lima) variabel yang masuk dalam kandidat multivariate setelah dilakukan analisis dengan menggunakan SPSS menggunakan metode Backward-LR yang paling signifikan atau paling dominan dengan kejadian ISPA yaitu ventilasi $(\mathrm{P}=0,003$, $\mathrm{OR}=9,611)$ dan kepadatan penghuni $(\mathrm{P}=0,000$, $\mathrm{OR}=17,297)$.

Jadi dari ke dua variabel yang paling signifikan tersebut untuk urutan pertama yaitu kepadatan penghuni karena memiliki nilai OR yang lebih besar dari nilai OR ventilasi yaitu 17,297 yang berarti kepadatan penghuni yang padat akan menimbulkan penyakit ISPA $17 \mathrm{x}$ dibandingkan rumah dengan kepadatan penghuni yang memenuhi syarat setelah dikontrol oleh luas ventilasi. Walaupun padat, akan tetapi jika luas ventilasinya baik $2 \mathrm{x}$ lipat penyakit ISPA tidak akan terjadi. Apabila ruangan sempit dan penghuni banyak untuk ventilasi bisa dibuat lebih besar.

Hasil penelitian tersebut menunjukkan bahwa faktor risiko terhadap kejadian ISPA sifatnya tidak tunggal, artinya faktor risiko yang satu dengan faktor risiko lainnya saling berkaitan dalam mempengaruhi kejadian ISPA.

Lingkungan fisik rumah dan PHBS yang tidak memenuhi syarat tetap menjadi risiko terjadinya ISPA pada balita. Oleh karena itu, upaya pencegahan ISPA perlu memperhatikan faktor lingkungan fisik rumah dan PHBS. Menurut WHO rumah sehat adalah suatu struktur fisik yang dipakai orang atau manusia untuk tempat berlindung, dimana lingkungan dari struktur tersebut termasuk juga fasilitas dan pelayanan yang diperlukan, perlengkapan yang berguna untuk kesehatan jasmani dan rohani serta keadaan social yang baik untuk keluarga dan individu.

\section{SIMPULANDAN SARAN}

pulan : Berdasarkan pada hasil penelitian dan pembahasan dapat diambil simpulan yaitu Ventilasi yang tidak memenuhi syarat dari keseluruhan kasus dan kontrol 47 rumah dan ventilasi yang memenuhi syarat 23 rumah. Ada hubungan yang bermakna antara luas ventilasi rumah dengan kejadian ISPA $(\mathrm{p}=0,000$; OR = 14,222). Pencahayaan yang tidak memenuhi syarat dari keseluruhan kasus dan kontrol 61 rumah dan pencahayaan yang memenuhi syarat 9 rumah. Tidak ada hubungan yang bermakna antara pencahayaan rumah dengan kejadian ISPA 
$(\mathrm{p}=0,153 ; \mathrm{OR}=4,125)$. Jenis lantai yang tidak memenuhi syarat dari keseluruhan kasus dan kontrol 18 rumah dan jenis lantai yang memenuhi syarat 52 rumah. Tidak ada hubungan yang bermakna antara jenis lantai rumah dengan kejadian ISPA $(p=0,412 ; \mathrm{OR}=1,833)$. Jenis dinding yang tidak memenuhi syarat dari keseluruhan kasus dan kontrol 5 rumah dan jenis dinding yang memenuhi syarat 65 rumah. Tidak ada hubungan yang bermakna antara jenis dinding rumah dengan kejadian ISPA $(p=1,000$; $\mathrm{OR}=1,547)$. Kepadatan penghuni yang tidak memenuhi syarat dari keseluruhan kasus dan kontrol 30 rumah dan kepadatan penghuni yang memenuhi syarat 40 rumah. Ada hubungan yang bermakna antara kepadatan penghuni dengan kejadian ISPA $(\mathrm{p}=0000 ; \quad \mathrm{OR}=15,000)$. Kelembaban yang tidak memenuhi syarat dari keseluruhan kasus dan kontrol 49 rumah dan kelembaban yang memenuhi syarat 21 rumah. Ada hubungan yang bermakna antara kelembaban dengan kejadian ISPA ( $\mathrm{p}=0,009$; OR $=5,053)$. Suhu yang tidak memenuhi syarat dari keseluruhan kasus dan kontrol 44 rumah dan suhu yang memenuhi syarat 26 rumah. Ada hubungan yang bermakna antara suhu dengan kejadian ISPA $(p=0,026 ; \quad$ OR $=3,574)$. Kebiasaan merokok yang tidak memenuhi syarat dari keseluruhan kasus dan kontrol 58 rumah dan kebiasaan merokok yang memenuhi syarat 12 rumah. Tidak ada hubungan yang bermakna kebiasaan merokok anggota keluarga responden dengan kejadian ISPA ( $\mathrm{p}=0,751$; OR $=0,667)$. Bahan bakar memasak keseluruhan sudah memenuhi syarat baik kasus dan kontrol yaitu 70 rumah. Tidak ada hubungan yang bermakna bahan bakar memasak anggota keluarga responden dengan kejadian ISPA. Penggunaan obat nyamuk keseluruhan sudah memenuhi syarat baik kasus dan kontrol yaitu 70 rumah. Tidak ada hubungan yang bermakna penggunaan obat nyamuk anggota keluarga responden dengan kejadian ISPA. Hasil uji multivariate menggunakan regresi logistic dengan metode Backward-LR didapatkan hasil variabel yang signifikan yaitu ventilasi $(\mathrm{P}=0,003, \mathrm{OR}=9,611)$ dan kepadatan penghuni $(\mathrm{P}=0,000, \mathrm{OR}=17,297)$.

Saran : Bagi Puskesmas 1 Purwokerto Timur Meningkatkan sistem kewaspadaan dini terhadap kejadian ISPA melalui peningkatan pengetahuan, sikap dan perilaku ibu mengenai pentingnya sanitasi fisik rumah yang sehat dengan memberikan penyuluhan secara rutin kepada setiap ibu misalnya pada acara pertemuan posyandu dan dilakukan pengecekan berulang agar apa yang disampaikan menjadi sebuah kebiasaan. Bagi Responden yaitu eningkatkan Perilaku Hidup Bersih dan Sehat (PHBS) dalam keluarga dengan cara tidak merokok di dalam rumah, tidak menggunakan obat nyamuk yang dapat mengganggu pernafasan dan tidak menggunakan kayu bakar untuk keperluan memasak sehari-hari. Menjaga kebersihan rumah seperti menyapu lantai, mengepel lantai dan membersihkan debu-debu yang menempel pada dinding dan lantai rumah agar tidak dijadikan tempat perkembangbiakan kumat penyakit, membuka jendela setiap hari agar sirkulasi udara lancar dan cahaya matahari masuk ke dalam rumah.

\section{Daftar Pustaka}

Achmadi, Umar Fahmi, 2008. Manajemen Penyakit Berbasis Wilayah. Jakarta : Universitas Indonesia Press.

Aris Santjaka, 2011, Statistik Untuk Penelitian Kesehatan. Yogyakarta : Nuha Medika

Aziz Alimul Hidayat, 2010. Metode Penelitian Kebidanan Teknik Analisis Data. Jakarta : Salemba Medika

Depkes RI, 2000. Pedoman Program Pemberantasan Penyakit Infeksi Saluran Pernafasan Akut. Direktorat PPM \& PL. Jakarta

2006. Pusat Promosi Kesehatan, 2006, Perilaku Hidup Bersih dan Sehat di Rumah Tangga, Jakarta

2010. Profil Kesehatan Indonesia. Jakarta : Departemen Kesehatan Republik Indonesia

2011. Kualitas Udara dalam Rumah terhadap ISPA pada Balita. Jakarta : Direktorat Jenderal Pengendalian Peyakit dan Penyehatan Lingkungan.

Dinas Kesehatan Provinsi Jawa Tengah, 2013, Profil Kesehatan Provinsi Jawa Tengah. Semarang

Kabupaten Banyumas, 2016. Profil Kesehatan Kabupaten Banyumas. Banyumas

Djasio Sanropie, dkk 1989. Pengawasan kesehatan lingkungan permukiman untuk institusi pendidikan tenaga sanitasi kesehatan lingkungan , Jakarta ; erlangga 
Ema Setianingrum, 2013. Hubungan Faktor Lingkungan Fisik Rumah Dengan Kejadian ISPA Pada Balita di Desa Kalitinggar Kecamatan Padamara Kabupaten Purbalingga Tahun 2013. Purwokerto : Kementrian Kesehatan Republik Indonesia Politeknik Kesehatan Kemenkes Semarang Jurusan Kesehatan Lingkungan Purwokerto Program Studi D III Kesehatan Lingkungan Purwokerto

Embriyowati Catiyas, 2012. Faktor-faktor Yang Berhubungan dengan Kejadian ISPA pada Balita di Wilayah Kecamatan Gombong Kabupaten Kebumen Jawa Tengah Tahun 2012. Depok : Fakultas Kesehatan Masyarakat Program Sarjana Kesehatan Masyarakat.

Eva Supriatin, 2013. Hubungan Faktor-faktor dengan Kejadian ISPA pada Balita di Puskesmas X Kota Bandung. Jawa Barat: Sekolah Tinggi Ilmu Keperawatan. http://ejournal.bsi.ac.id/assets/files/Jurna 1_Ilmu_Keperawatan._Vol_.I_.No_.1_.S eptember 2013 Eva Supriatin 3946.pdf . Diakses pada tanggal 26 Desember 2017. Pukul 19.38 WIB

G. Kartasapoetra dan H. Marsetyo, 2010. Ilmu Gizi, Korelasi Gizi, Kesehatan dan Produktivitas Kerja, Jakarta : Rineka Cipta.

Herniwati, 2006. Studi Korelasi Faktor Ventilasi, Kepadatan Penguhuni dan Pencemaran Udara di Dalam Rumah dengan Kejadian ISPA pada Balita di Kelurahan Mersi Kecamatan Purwokerto Timur Kabupaten Banyumas Tahun 2006. Purwokerto : Kementrian Kesehatan Republik Indonesia Politeknik Kesehatan Kemenkes Semarang Jurusan Kesehatan Lingkungan Purwokerto Program Studi D IV Kesehatan Lingkungan Purwokerto.

H. J. Mukono, 2006. Prinsip dasar kesehatan lingkungan. Surabaya: Airlangga University Press

Ike Suhandayani (2007). Faktor-Faktor yang Berhubungan dengan Kejadian ISPA pada Balita di Puskesmas Pati I Kabupaten Pati Tahun 2006. Semarang : Fakultas Ilmu Keolahragaan Jurusan Kesehatan Masyarakat
Indan Entjang, 2003, Mikrobiologi Dan Parasitologi Untuk Akademi Keperawatan Dan Sekolah Tenaga Kesehatan Yang Sederajat, Bandung : PT Citra Adita Bakti.

Irma Suryani, dkk, 2015. Hubungan Lingkungan Fisik dan Tindakan Penduduk dengan Kejadian ISPA pada Balita di Wilayah Kerja Puskesmas Lubuk Buaya. Padang : Fakultas Kedokteran Universitas Andalas Padang. http://download.portalgaruda.org/article. php? article $=300129 \&$ val $=7288 \&$ title $=\mathrm{H}$ ubungan\%20Lingkungan $\% 20$ Fisik\%20d an\%20Tindakan\%20Penduduk\%20deng an\%20Kejadian\%20ISPA\%20pada\%20 Balita\%20di\%20Wilayah\%20Kerja\%20 Puskesmas\%20Lubuk. Diakses tanggal 28 Desember 2017 Pukul 01.14 WIB.

Juli Soemirat Slamet. 2000. Kesehatan Lingkungan. Yogyakarta: Gadjah Mada University Press

Keputusan Menteri Kesehatan Republik Indonesia Nomor 1537.A/Menkes/SK/XII/2002 Tentang Pedoman Pemberantasan Penyakit Infeksi Saluran Pernafasan Akut Untuk Penanggulangan Pneumonia pada Balita

Lindawaty, 2010. Partikulat (PM 10 Udara Rumah Tinggal Yang Memepengaruhi Kejadian ISPA pada Balita (Penelitian di Kecamatan Mampang Prapatan,Jakarata Selatan tahun20092010). Tesis Fakultas Kesehatan Masyarakat Universitas Indonesia.Depok.

Mudehir, 2002. Hubungan faktor-faktor lingkungan rumah dengan kejadian penyakit ISPA pada Anak balita di Kecamatan Jambi Selatan tahun 2002. Tesis. FKM UI. Depok.

Notoatmodjo, Soekidjo. (1997). Ilmu Kesehatan Masyarakat. Jakarta: PT.Rineka Cipta

(2003). Ilmu Kesehatan Masyarakat Prinsip-Prinsip Dasar. Jakarta: Rineka Cipta. 
(2007). Kesehatan

Masyarakat. Yogyakarta: PT. Rineka Cipta

(2010). Ilmu Perilaku

Kesehatan. Jakarta: Rineka Cipta

Nurjazuli, 2009. Faktor Risiko Dominan Kejadian Pneumonia pada Balita di Puskesmas Kebumen. Semarang : Universitas Diponegoro

Nur Mustofa, 2000, Studi Komparasi antara Rumah yang dihuni Anak Balita ISPA dengan Rumah yang dihuni Anak Balita bukan ISPA Di Desa Patemon, Kecamatan Kandangan, Kabupaten Temanggung. Purwokerto : Kementrian Kesehatan Republik Indonesia Politeknik Kesehatan Kemenkes Semarang Jurusan Kesehatan Lingkungan Purwokerto Program Studi D III Kesehatan Lingkungan Purwokerto

Permenkes No.1077 tahun 2011. Tentang Pedoman Penyehatan Udara Dalam Ruang Rumah. Jakarta

Profil Puskesmas 1 Purwokerto Timur Kabupaten Banyumas 2016

Radhyallah, 2009, Faktor-Faktor Yang Berhubungan dengan Kejadian ISPA Berulang pada Balita Usia 36 - 59 Bulan di Puskesmas Salotungo Watan Soppeng. Makassar: Universitas Hasanuddin Makassar.

Rahmayatul Fillacano, 2013. Hubungan Lingkungan Dalam Rumah Terhadap ISPA Pada Balita di Kelurahan Ciputat Kota Tangerang Selatan Tahun 2013. Jakarta : Program Studi Kesehatan Masyarakat Fakultas Kedokteran Dan Ilmu Kesehatan Universitas Islam Negeri Syarif Hidayatulla.

Rusti Setiyowati, 2006, Studi Komparasi Antara Sanitasi Rumah Penderita ISPA Dengan Bukan Penderita ISPA Pada Balita Di Desa Kebumen Kecamatan Baturraden Kabupaten Banyumas Tahun 2006, Purwokerto : Politeknik Kesehatan Kementerian Kesehatan Semarang Jurusan Kesehatan Lingkungan.

R. Topan Aditya Rahman. 2015. Analisis Statistik Penelitian Kesehatan. Bogor : Penerbit IN MEDIA
Safitri,Aprinda Dwi dan Ismail,Sofyan, 2010. Hubungan Tingkat Kesehatan Rumah Dengan Kejadian ISPA Anak Balita DI Desa Labuhan Kecamatan Labuhan Badas Kabupaten Sumbawa. Jurnal Kesehatan Lingkungan, Vol.3,No.2,Januari 2007:139-150. http://download.portalgaruda.org/article. php?article $=18178 \&$ val $=1132$. Diakses pada tanggal 15 Januari 2018 pada pukul 20.21 WIB.

Sherly Candra Dewi (2014). Hubungan Kondisi Fisik Rumah dengan Kejadian ISPA Balita di Wilayah Kerja Puskesmas 1 Purwokerto Timur Desa Arcawinangun Tahun 2014. Purwokerto : Kementrian Kesehatan Republik Indonesia Politeknik Kesehatan Kemenkes Semarang Jurusan Kesehatan Lingkungan Purwokerto Program Studi D III Kesehatan Lingkungan Purwokerto

Soewasti S.S., dkk. (2000). Hubungan Kondisi Perumahan Dengan Penularan Penyakit ISPA dan TB Paru. Dalam Media Litbang Kesehatan, Volume X, No.2: 27-31.

https://media.neliti.com/media/publicatio ns/158265-ID-hubungan-kondisiperumahan-dengan-penula.pdf . Diakses tanggal 16 Januari 2017 Pukul 02.12 WIB

Srikandi Fardiaz. 1992. Polusi Air dan Udara. Yogyakarta: Penerbit Kanisius

Suryanto, 2003. Hubungan Sanitasi Rumah dan Faktor Intern Anak Balita dengan Kejadian ISPA pada Anak Balita. Skripsi. Surabaya: Fakultas Kesehatan Masyarakat Universitas Airlangga.

Sutanto Priyo Hastono dan Luknis Sabri. 2011. Statistik Kesehatan. Jakarta: Rajawali Pers

Tombili A, 2006, Studi Korelasi PHBS Tatanan Rumah Tangga Dengan ISPA Pada Balita Di Wilayah Kerja Puskesmas Tawanga Kecamatan Wawotobi Kabupaten Konawe Tahun 2006, Kendari.

Tri Cahyono, 2017. Penyehatan Udara. Yogyakarta: Andi (Anggota IKAPI)

Undang - Undang Republik Indonesia No. 36 Tahun 2009 Tentang Kesehatan 
Vinna Mairuhu dkk. 2012. Faktor yang Berhubungan dengan Kejadian ISPA pada Balita di Pulau Barrang Lompo Kecamatan Ujung Tanah Kota Makkasar: Makkasar: Bagian Kesehatan Lingkungan Fakultas Kesehatan Masyarakat Universitas Hasanuddin.

Vita Ayu Oktaviani, 2009. Hubungan Antara Sanitasi Fisik Rumah dengan Kejadian Infeksi Saluran Pernapasan Atas (ISPA) pada Balita di Desa Cepogo Kecamatan Cepogo Kabupaten Boyolali Surakarta : Program Studi Kesehatan Masyarakat Fakultas Ilmu Kesehatan Universitas Muhammadiyah Surakarta

Waryana, 2010. Gizi Reproduksi, Yogyakarta : Pustaka Rihama

Wattimena,C.S, 2004. Faktor Lingkungan Rumah yang Mempengaruhi Hubungan Kadar PM10 dengan kejadian ISPA pada Balita di wilayah Puskesmas Curug Kabupaten Tangerang tahun 2004. Depok : FKM Universitas Indonesia.

Yulian Irfan Widodo (2014). Hubungan Lingkungan Fisik Rumah dengan Kejadian Penyakit Infeksi Saluran Pernapasan Akut (ISPA) pada Balita di Desa Karangrau Kecamatan Banyumas Kabupaten Banyumas Tahun 2014. Purwokerto : Kementrian Kesehatan Republik Indonesia Politeknik Kesehatan Kemenkes Semarang Jurusan Kesehatan Lingkungan Purwokerto Program Studi D III Kesehatan Lingkungan Purwokerto 